\title{
LA ENSEÑANZA DE LA HISTORIA DE LA FILOSOFÍA MEDIEVAL. UNA EXPERIENCIA DE VEINTICINCO AÑOS
}

\author{
Josep Manuel Udina \\ Universitat Autònoma de Barcelona
}

\section{RESUMEN}

Acorde con el talante del presente volumen, de homenaje y de agradecimiento personal a un reconocido medievalista, este artículo tiene un carácter estrictamente personal, aunque su contenido es bien académico. Recoge la experienca del autor en sus 25 años de profesor de Historia de la filosofía medie$v a l$, dedicación a la que llego de modo un tanto accidental en 1978 y con un alumnado, en los primeros años del recién finiquitado nacional-catolicismo franquista, cuya actitud era de alergia y prevención ante todo lo que sonase a cristiano o religioso. Desde hace años, en cambio, la actitud de los alumnos refleja un interés y una curiosidad por lo medieval que hace cinco lustros eran inimaginables. El autor confiesa que tales cambios no le han hecho variar los contenidos docentes (éstos son los que hay, y han de impartirse) pero explica las variaciones, en la manera de darlos con el paso del tiempo, derivadas de la diversa situación socio-cultural y de la correspondiente actitud del alumnado.

Palabras clave: docencia de la filosofía, antología de textos, dossier de materiales, lectura directa de los autores, libertad de asistencia a clases, evaluación mediante comentario de textos

\begin{abstract}
According to the mood of the present volume - homage and personal gratitude for a celebrated medievalist-, this article is strictly personal but its contents are still very academic. It gathers up the experience of the autor in his 25 years as professor of «History of medieval Philosophy». He started the dedication a bit by chance in 1978, with students of the first years after the ending of Franco national-catholicism, whose attitude was of allergy and prevention from everything christian or religlous. Since several years, on the contrary, the students attitude towards medieval things shows an interest and curiosity inconceivable 25 years ago. The autor acknowledges that these changes have not made him alter the contents of his teaching (they are always the same and must be given) but he explains the different way of explaining the subject along the years arose from the diverse sociocultural situation and the consequent students attitude.
\end{abstract}

Key words: Philosophy teaching, Texts anthology, Material dossier, Direct reading of authors, Freedom to attend classes, Evaluation through text commentary

\section{PRESENTACIÓN}

Quien escribe estas líneas inició su docencia en la Universidad (en la Autònoma de Barcelona) en el curso 1972-73, como adjunto contratado; y seis años después (curso 1978-79) empezó a impartir la asignatura de Historia de la filosofía medieval (entonces obligatoria, y actualmente troncal en su primer semestre y obligatoria en el segundo, en dicha universidad). Con el presente son, pues, veinticinco los años que lleva ya impartiéndola. Su intención, aquí, es 
hablar de esta su experiencia de un cuarto de siglo de docencia de una materia tan peculiar como esta: la de la historia del pensamiento en la Edad Media.

El presente artículo corresponde originariamente a la aportación que su autor hiciera a un Congreso de profesores universitarios del área de Filosofía, de tema libre y sin previsión de Actas del mismo. ${ }^{1}$ Su publicación aquí no es, sin embargo, puramente oportunista; más bien quiere expresar su reconocimiento al doctor Joaquín Lomba por parte de alguien que en su momento se viera como llevado, un tanto accidentalmente, a dedicarse a la filosofía medieval y que en esa su dedicación cumple ya cinco lustros. ${ }^{2}$ De ahí, también, el tono directo y personal -el de quien, a fin de cuentas, no expone sino su experiencia- de las páginas que siguen: unas páginas que en adelante hablarán, por lo mismo, en primera persona del singular. Aunque esta no parezca ser una fórmula excesivamente académica, aquello a lo que con ella se refieran las mismas sí será, en cambio, estrictamente académico.

Recojo, para empezar, el pequeño inciso del párrafo anterior relativo al hecho de que fue «un tanto accidentalmente» como en su momento me vi llevado a dedicarme a la filosofía medieval. En efecto: en 1966 me había «licenciado» en filosofía con HEGEL y su Fenomenología del espiritu (si me es permitido referirme así a mi trabajo ad gradum en la especialidad, final de carrera: lo que entonces llamábamos la «tesina»); ${ }^{3}$ y diez años después, en 1976, me había «doctorado» (valgan de nuevo las comillas) en el filósofo alemán del, desde hace poco, pasado siglo XX Ernst BLOCH (1885-1977). ${ }^{4}$ Fue Bloch un pensador entre posthegeliano y neomarxista, así como entre judío descreído, pero mesiánico, y ateo militante, pero cristiano «en la herencias: el pensador de la esperanza, en el sentido de una utopía concreta e incluso de una materia utópica. Ni por Hegel ni por Bloch era, pues, aquél el más adecuado curriculum (más bien era, al respecto, un verdadero ridiculum) para tener esperanzas concretas de acabar dedicándome preferentemente a lo medieval, y no a lo contemporáneo.

Pero la vida es así. En 1978 no había nadie, en mi Departamento, que pudiera o quisiera impartir la medieval; y me ofrecí a hacerlo, oferta que me fue aceptada en seguida, ni que fuese por tener yo también, desde 1970 , la licenciatura en teología. ${ }^{5}$ No hace falta recordar a Émile BRÉHIER negando que pudiese haber filosofía cristiana si lo que en la edad media había era pura y dura teología: no es preciso recordarlo, digo, parà saber que lo teológico y lo medieval andan muy unidos. Otra cuestión es si lo teológico comporta la negación de pensamiento, cuestión que acertó a zanjar de una vez por todas Pierre VIGNEaux al darle a su conocida y

1 El Congreso en cuestión se celebró en Valencia, los días 6,7 y 8 de febrero de 2003 , en la Facultad de Filosofía y Letras de la Universidad de dicha ciudad.

2 Desde 1990 el profesor LOMBA ha sido, en efecto, inspirador y alma tanto de la Sociedad Española de Filosofía Medieval como de su correspondiente Revista (de las que el cuerpo activo y eficiente ha sido - hay que decirlo todo - el doctor Jorge Manuel AYALA); y quien firma estas páginas no sólo les ha acompañado siempre como vocal de la Junta de dicha Sociedad, sino que además ha experimentado tener en el doctor Lomba y en ésta, así como en los tres congresos por ella organizados (en 1990, 1994 y 1998), respaldo y acicate para una tal dedicación a lo medieval.

3 Josep MANUEL Udina, Aproximación a la "Fenomenología del espíritu» de Hegel: la historia del concepto y el concepto de la historia, Universidad de Barcelona, 1966, $353 \mathrm{p}$.

4 JOSEP MANUEL UDINA, La constitución utópica de lo humano. Introducción y anotaciones críticas a la filosofia de Ernst Bloch, Universidad de Barcelona, 1976, 3 vols., 824 p.

5 Por la entonces Facultad de Teología de Sant Cugat del Vallès (Barcelona). No había sido, por lo demás, incoherente con mi anterior currículum el que mi correspondiente trabajo ad gradum en la especialidad, final de caTrera, versase sobre La historia de la fe y de la comunidad cristianas según la filosofía de la historia de G.W.F. Hegel, Sant Cugat del Vallès, Barcelona 1970, 47 p. 
densa monografía, de 1934, el título de $E l$ pensamiento medieval, y no el de «La filosofía medieval». ${ }^{6}$

Todos sabemos lo que significa (en tiempo, esfuerzo y nervios) impartir una asignatura nueva. Por esto, cuando - al acabar el curso de mi «estreno» medievalista- se insinuó en mi Departamento que la Historia de la filosofía medieval volvería a darla quien lo había hecho en años anteriores, me planté y exigí seguir dando aquel curso, ni que fuese para amortizar el trabajo invertido en él. Fue, pues, por pura casualidad como empezó y por impura tozudez mía como continuó mi aventura, de ya cinco lustros, con la edad media. Y digo aventura por no decir - como debiera - buenaventura, pues esto es lo que ha sido: al menos si se la mira desde mí y ex eventu (con perdón por el tecnicismo bíblico-exegético).

De entrada dicha aventura no fue, sin embargo, fácil ni alentadora. En aquelia época - la del recién nacido postfranquismo (por tanto, la inmediatamente posterior al nacional-catolicismo) - buena parte del alumnado recibía con recelo y prevención todo lo que sonase a religioso. El pensamiento medieval (me refiero siempre, por descontado, al pensamiento medieval occidental) es básicamente judío, musulmán o, sobre todo, cristiano. De ahí que fuera comprensible la reacción de los jóvenes universitarios, dado el confesionalismo que todavía imperaba en su entorno y en el que habían sido educados. Con los años, el panorama ha canviado totalmente. A la aprensión y al recelo del alumnado de aquellos tiempos iniciales han sucedido en los alumnos de la última década (nacidos ya en el postfranquismo y receptores de una educación claramente aconfesional) una actitud receptiva y una curiosidad por lo desconocido que no imaginé entonces que pudieran darse nunca respecto del pensamiento medieval.

Ni frente a una dominante animadversión ni ante tan diversa favorable predisposición de sus destinatarios jamás, a lo largo de los años, ha variado mi docencia en cuanto a sus contenidos: los contenidos son los que hay, y han de impartirse en la asignatura (independientemente de la actitud de los matriculados). Pero el cambio de la situación socio-cultural y de la correspondiente actitud de los alumnos sí que han determinado variaciones en cuanto a la atención y al tiempo dedicados a unos u otros puntos y aspectos de dichos contenidos de la asignatura. A la no variación de contenidos y a la variación del modo de atender a ellos dedicaré las dos restantes partes de esta exposición. Si una corresponde al fondo homogéneo de un cuadro, la otra representa las pinceladas que dan color y movimiento a sus figuras.

Demos por irresoluble el problema de la delimitación del período medieval, sobre todo respecto de su inicio: Boecio y el Pseudo-Dionisio, en el s. VI, ¿ son ya medievales, o siguen siendo antiguos?; ¿hay que esperar al nacimiento del islam o al renacimiento carolingio para hablar de edad media?, ¿o es que ésta sólo existe al llegar el feudalismo? Sea de ello lo que sea, el pensamiento medieval - ya se ha dicho- es, en cualquier caso, inseparable de la dimensión religiosa, sea ésta cristiana, judía o musulmana. Es inseparable, por lo mismo, tanto de la Biblia como del Corán, tanto del judaísmo veterotestamentario y de los orígenes del cristianismo como de la figura de Mahoma y de su doble empeño: el de brindar al pueblo una fe sencilla (la Encarnación y la Trinidad cristianas habían de parecerle indigeribles a un monoteísmo fervoroso) y el de brindarle, a la vez, una fe atractiva (el tabú gnóstico-maniqueo de la sexualidad amargaba innecesariamente la conciencia judeo-cristiana). ${ }^{7}$

6 Pierre Vigneaux, La pensée au moyen âge, A. Colin, París 1938. Traducida al castellano (Fondo de Cultura Económico [Breviarios $n^{\circ}$ 94], México 1954; $8^{\mathrm{a}}$ reimpresión, 1993), la obra ha sido incluso reeditada ligeramente ampliada en francés en 1990.

7 Es posible que estas afirmaciones sean tildadas de simplistas, pero responden a mi más firme convicción 
Por ello tomé ya de entrada y he seguido siempre tomando como punto de partida de la asignatura una introducción referida a los orígenes del cristianismo. Ellos remiten asimismo tanto al espíritu, por así llamarlo, bíblico-semítico como al talante greco-helenístico. (El fenómeno histórico-cultural de lo cristiano no se entiende, en efecto, sin referencia a la vez a una y otra de ambas raíces o dimensiones). Pero hablar de la filosofía griega no puede hacerse sin remitir a Homero y a su esfuerzo de racionalización del panteón épico ${ }^{8}$ como tampoco puede hablarse de la religión judía sin remitir a sus orígenes mosaicos en la dinastía XIX del Imperio nuevo faraónico. De ahí que hablar de Troya —-mediante Homero-y de la coetánea huída de Egipto por parte de los israelitas - a través de los diversos autores y documentos del Pentateuco-siempre me ha parecido la mejor manera, la manera imprescindible, de entrar en lo medieval. Así lo hice en mi estreno como profesor de la materia y sigo haciéndolo cinco lustros después; y lo hago incluso contraponiendo hasta cierto puñto lo griego y lo semítico, como simbolización, respectivamente, de un fatalismo determinista y de una libertad responsabilizada frente a la realidad en su conjunto; pero sólo hasta cierto punto, puesto que no identifico sin más ni el logos calculador con Grecia ni la fe en lo imprevisible con Israel, sino que más bien caracterizo con ello las dos caras de todo ser humano, la doble alternativa que cualquier pueblo y cada individuo tienen de enfrentarse al mundo. Por lo que he visto, semejante comienzo de curso $a b$ ovo suscita un considerable interés entre los alumnos, aparte de que permite un rápido repaso de la filosofía antigua (es decir: de la filosofía griega) y, así, de la asignatura que precede a la mía: la de Historia de la filosofia antigua. A la vez, al hablar de los origenes del cristianismo es inexcusable referirse a los pensadores de los primeros siglos de nuestra era, a la patrística tanto griega como latina y a representantes tan significativos de una y otra como Orígenes de Alejandría y Agustín de Hipona, temas y autores - todos ellos- correspondientes al helenismo y, por tanto, a la mencionada Historia de la filosofia antigua, pero de los que en ésta no se trata (porque no son «griegos» sino «cristianos», suele decirse).

Una tal introducción al curso supone, obviamente, recortar el tiempo disponible para atender al pensamiento propiamente medieval. En el plan de estudios antiguo (asignatura anual), dicha parte introductoria me ocupaba todo el primer trimestre, quedando sólo los otros dos para

de que el cristianismo oficial u «ortodoxo», al pueblo, le resultaba — como le sigue resultando hoy- bastante incomprensible (en cuanto a su dogmática cristológico-trinitaria) y harto impracticable (en cuanto a su moral obsesivamente centrada en la sexualidad). En el primer sentido, la reducción estrictamente monoteísta que el islam suponía («sólo Dios es Dios; y Mahoma [sólo es, como Moisés o Jesús,] su profeta») -volviendo, al respecto, al antecedente judaico del cristianismo- significaba no sólo facilitar al creyente musulmán su profesión de fe, sino que a la vez evitaba cualquier posible deslizamiento de la fe popular hacia politeísmos más o menos crípticos (aunque formalmente siempre rechazados y negados); la fe cristiana popular nunca acaba, en efecto, de digerir en estricto monoteísmo un Jesucristo Dios al lado de Dios Padre, y en cualquier caso ha-tendido a convertir a Jesús en Pantocrator (Todopoderoso), sin duda un equivalente del Dios Omnipotente del judaísmo (el Dios Padre de la fe trinitaria) o ha sido incapaz de hallar representación antropomórfica para el Espíritu Santo, realidad tan «personal» como la del Padre y la del Verbo o Hijo (a diferencia de lo que sí ha hecho con la de éstos). En cuanto al segundo aspecto, el de la obsesión sexualista de la moral oficial cristiana, adviértase que propiamente poco tiene que ver con el problema de la desigualdad por razón del género (predominio machista o sensibilidad feminista): la subordinación de la mujer al hombre, entendido éste como varón, no ha sido ni es menor en el islam que la que se ha dado y se da tanto en el cristianismo como en el judaísmo, e incluso - también se ha de decir- que la que se daba en el mundo griego clásico o en el helenístico greco-latino; una vez puntualizado esto, hay que reconocer como peculiaridad oriental, en contraposición al temple más típicamente cristiano-occidental, una sensibilidad-sensualidad como mucho más a flor de piel, peculiaridad que el islam supo respetar e incluso fomentar al negarle cualquier significado peyorativo por lo que a la ética o a la religiosidad se refiere, cosa bien distinta de lo que sucedía en el cristianismo (aunque en éste no fuera así precisamente por imperativo evangélico, sino más bien como legado judaico-paulino y sobre todo como fruto de ulteriores influjos dualistas - gnósticos y maniqueos - o simplemente neoplatónicos).

8 Esta referencia inicial a la literatura homérica - y, más específicamente, al tratamiento en ella del tema religioso-, cual inexcusable punto de referencia para entrar en el pensamiento filosófico antiguo, halla su más reciente ejemplificación en la obra de Julio QUESADA, Otra historia de la filosofía. Por qué pensamos lo que pensamos, Ariel, Barcelona 2003, p. 19 y ss. 
el resto (para la edad media como tal); en el plan posterior — de dos semestres (en la práctica, dos cuatrimestres; iy de hecho no son, uno y otro, sino trimestres!)_-, la Historia de la filosofía medieval I relega el pensamiento en el mundo islámico al principio de la Historia de la filosofía medieval II; con lo que también el segundo semestre se abre con una introducción equivalente a la del primero, relativa ahora no ya a la Biblia y a Grecia sino al Corán y a la irrupción en la Europa latina de las traducciones - a través del árabe- de las obras de los pensadores griegos: encuadre, éste, de nuevo imprescindible para entender el correspondiente pensamiento medieval musulmán, judío o cristiano. Si en el primer semestre los «platos fuertes» del curso eran Orígenes, Agustín (con el así llamado agustinismo político) y Escoto Eriúgena, en el segundo lo son: los pensadores islámicos (musulmanes y judíos), Anselmo (con su polémico argumento) y el Aquinate (con sus cinco vías), quedando el nominalismo y Occam como peldaño del tránsito al Renacimiento, a la Reforma y a la modernidad; dos semestres un tanto desequilibrados por causa de la más amplia introducción inicial del curso.

En cualquier caso, la intención del curso ha sido siempre - y es aún hoy - conseguir que los alumnos lean, siquiera una vez en su vida, textos de autores medievales. Por ello mis sesiones académicas (sencillamente, las clases) se centran en el comentario de texto, disponiendo el alumno de una Antología (de más de 200 páginas) preparada por mí al efecto desde hace ya dos décadas. ${ }^{9}$ A su vez, dichos alumnos han de hacer y dar razón de unas lecturas obligatòrias (a escoger entre diversos títulos). Fruto de dicha obligación han sido comentarios del alumnado como los de que La creación del mundo, de Filón de Alejandría, La consolación de la filosofía boeciana, La jerarquía celestial, del Areopagita, La ciudad ideal, de Al-Farabi, o la Ética abelardiana les han resultado, a uno u otro, «un descubrimiento»; y también preguntas como la de si el autor de las Confesiones era «una especie de talibán». Y para el caso, tanto da que el interesado sea de los que reconocen cursar la Historia de la filosofía medieval únicamente por ser obligatoria como de quienes dicen interesarse por ella para conocer mejor el cristianismo o el islam. Por lo demás, la evaluación de tales lecturas forma parte de la del curso, en la que cuenta como factor decisivo la calificación del comentario de texto final de semestre (comentario de un par de textos de la mencionada Antología: de aquellos textos presentados, contextualizados y comentados por mí en clase). No me interesa la pura memorización (de autores - de sus vidas, de sus obras o de su aportación a la historia del pensamiento- ni de temas); del estudiante exijo, sobre todo, que haya leído algunos textos medievales y que me deje constancia de que sabe entenderlos, interpretarlos y juzgarlos atinadamente al hacer un comentario de los mismos.

\section{III}

Las generaciones pertenecientes ya a la transición democrática han ido teniendo $-\mathrm{y}$ me refiero a Cataluña, que es lo que conozco- una educación más bien demasiado aconfesional, cuando no anticonfesional; y digo «demasiado» porque, si está bien el no confesionalismo educacional, no lo están tanto la ignorancia y la incultura en temas religiosos. ${ }^{10}$ De imponer una

9 Corregida cada año, y en alguna ocasión aumentada en sus textos, dicha Antologia de textos d'història de filosofia medieval tiene una edición limitada cada curso a cargo del Servicio de Publicaciones de la Universitat Autònoma de Barcelona, para su adquisición por los alumnos matriculados y por quien quiera. Su última edición (204 p.) es, pues, de octubre de 2003.

10 Entre otros no menos graves, un serio error de la transición postfranquista — tan aireada de «modélica»fue el de dar pie a una tal ignorancia e incultura de las nuevas generaciones; y responsables por igual de semejante error fueron tanto las autoridades políticas como la jerarquía eclesiástica españolas, y acaso en mayor grado esta última. Los obispos no quisieron, en efecto, renunciar a la catequesis y al adoctrinamiento católicos en la enseñanza obligatoria, menospreciando el carácter laico del estado que la Constitución de 1977 proclamaba; pero lo único que con ello conseguían fue que los políticos confundiesen la laicidad de la enseñanza con la ausencia de toda edu- 
religión —una formación religiosa - se ha pasado a no dar ni tener ninguna información, ninguna cultura sobre el tema religioso. Mas, falto de tal bagaje, ¿cómo puede uno acercarse al arte occidental? ¿o cuántas notas necesitarán las obras clásicas de la literatura para que el lector entienda mil alusiones y referencias impregnadas de una cultura religiosa de siglos? Sea lo que sea de este problema, lo cierto es que a partir de hace diez o doce años el prejuicio del alumnado frente a lo medieval se fue convirtiendo en predisposición favorable hacia el tema. Pero, a la vez, no ha hecho más que crecer el desconocimiento de dicho alumnado acerca de la Biblia y del Corán, del cristianismo y de las otras religiones, de las diferentes «confesiones» o Iglesias cristianas, de las distintas «órdenes» religiosas católicas, etc. —y sin saber algo de todo esto ¡bien poco inteligible resulta la historia del pensamiento medieval!-, y ha crecido hasta cotas inverosímiles («Trinidad» es sólo «nombre de mujer», y «Encarnación», «reencarnación» y «resurrección» son sinónimos, según algunas respuestas del breve test que, al principio de curso, presento al alumnạdo para que lo conteste).

Sin variar los contenidos, en los últimos lustros - primera pincelada sobre el fondo del cuadro- he tenido, pues, que ir insistiendo más en lo referente a judaísmo y cristianismo que en lo referente al mundo griego, en la parte introductoria del curso (que se ha confirmado, así, como aún más necesaria). Por lo demás, con las semanas lectivas que el nuevo plan de estudios perdió respecto del antiguo se acortaba considerablemente el tiempo disponible para el desarrollo académico de cada semestre; de ahí que la exigencia de no suprimir materia ha comportado que a la Antología de textos ya mencionada haya añadido yo desde hace años un Dosier (de más de 150 páginas) que incluye la «bibliografía general» del curso, 24 grandes «cuadros esquemáticos», tanto históricos como doctrinales, y otros «diversos materiales» (sobre distintos temas y autores). ${ }^{11}$ Así, desde el primer momento se da cuenta el alumno de que la asignatura ha sido pensada y está planificada en su totalidad, cosa que los estudiantes no siempre detectan -como ellos mismos comentan a veces- en las materias que cursan.

Pero acaso lo más importante y ventajoso de esta duplicidad de elementos que entran en juego en la docencia de la disciplina — segunda pincelada de dinamismo- es que, así, la asistencia a clase no se reduce a un pasivo escuchar al docente, sino que exige a la vez el trasiego de una Antología, con los textos de que se trata en la sesión, y de un Dossier al que se remite como ampliación de lo que se explica y (en el caso de los cuadros mencionados) como refuerzo gráfico de la exposición. El curso viene a ser una especie de puzzle que exige al alumno interactuar (lo cual le supondrá la efectiva toma de conciencia de que necesita un tiempo ulterior para reasumir, en privado, los temas, autores y textos en cuestión).

Pasemos, en fin, del alumno al profesor: tercera pincelada. Mi curso de Historia de la filosofía medieval es, y ha sido siempre, un curso de historia de la filosofia: no ha sido intento alguno de catequizar ni desaforada campaña antirreligiosa, y tampoco ha sido un proponer mi propia cosmovisión; simplemente, es una esforzada aproximación a los pensadores y a su Sitz. im Leben - tan distinto del nuestro- para así comprenderlos en su contexto y, desde la correspondiente comprensión de sus textos desde dentro, poderlos juzgar (és decir, tanto valo-

cación - en el sentido de información cultural — sobre el fenómeno histórico de las religiones (y entre nosotros, en concreto, sobre la tradición tanto judeo-cristiana como musulmana). En nuestros días, con la enésima reforma de la enseñanza que sin tino se empeña en imponer el gobierno de turno, es evidente que el viejo error sigue operando con virulencia, aunque ahora sea en el sentido de favorecer un reimplantamiento de la más rancia catequesis (de la mano de un reimplantamiento del más rancio nacionalismo español, siempre impuesto y centralista).

11 Como de dicha Antología, del Dossier d'història de la filosofia medieval. Programa de l'assignatura, bibliografia general $i$ materials de treball se hace también cada curso una edición limitada para los alumnos matriculados, pero abierta a quienes deseen adquirir el ejemplar, corregido oportunamente (corrección imprescindible por lo que respecta a la Bibliografía, que ha de ser siempre actualizada). La última edición (42 p. de bibliografía, con paginación independiente, y 134 p. de dosier propiamente dicho) es también de octubre de 2003. 
rar como criticar) con la mayor objetividad posible y, sólo entonces, con verdadera libertad. ${ }^{12}$ «Todo texto fuera de contexto es puro pretexto» es el lema favorito de mis clases (y a partir del segundo mes del curso suscita la sonrisa de los alumnos siempre que lo repito). Asimismo, entre los medievales no hay para mí «santos»: jamás digo san Agustín ni santo Tomás, y a uno y a otro, o al creador del «argumento anselmiano», me complace encontrarles «sombras» que contrasten con sus méritos y los relativicen, a la vez que los resaltan. ${ }^{13}$ En cuanto a los no santos, me gusta repetir que no es que merecieran menos que los otros ser reconocidos como tales: Orígenes, por ejemplo, es un perdedor porque la historia es así (el mencionado Agustín de Hipona fue, en cambio, un vencedor; pero acaso no mereció demasiado ser proclamado tal); ${ }^{14}$ en cuanto a Abelardo, ni es tan genial como algunos pretenden ni tan rebelde como la tradición lo ha presentado. Etcétera.

A mi convicción de que los contenidos del curso son los que hay y de que han de impartirse independientemente de la actitud del alumno o del tiempo que los planes de estudio concedan a la docencia, se añade -última pincelada - mi creencia de que la enseñanza es un ser-

12 Como ejemplo de crítica de escasa objetividad y, por lo mismo, de poca seriedad y validez, me complazco en presentar cada año al alumnado la que de la célebre prueba anselmiana se ofrece en ERNST BLOCH, Entremundos en la historia de la filosofía, Taurus (Ensayistas $n^{\circ} 245$ ), Madrid 1984, p. 60-65 (texto recogido casi íntegramente en el ya mencionado Dossier d'història de la filosofia medieval, ed. cit., p. 116-120): una crítica que se reduce - como reconoce el propio autor-a ser «extrínseca» y, así, bien «fácil», pero que por ello no tiene valor y resulta harto superficial y tópica (se limita a reproducir los argumentos ofrecidos por Gaunilón -rebatidos luego por Anselmo- y a su vez repetidos ya por Kant, y que no tienen en cuenta la epistemología propia del monje de $\mathrm{Bec}$, radicalmente distinta de la de sus críticos, que a veces ignoran -es el caso de Kant-el contexto mismo concreto de la prueba, que es el Proslogion, a fin de cuentas un libro de meditación religiosa); para una crítica de dicha crítica blochiana, cf. JoSEP MANUEL UdiNA, «Ernst Bloch, filòsof, com a medievalista», en Medievalia 10 (1992) 455-472, especialmente p. 467-470. Sólo si se esfuerza en ser bien objetiva puede la crítica de un autor ser verdaderamente libre: citicar lo que no se conoce o lo que ni se ha procurado comprender desde dentro, ni es justo ni puede justificarse en nombre de la libertad, pues en tal caso no es libertad lo que se da, sino ignorancia.

13 A Agustín volveré a referirme, al respecto, enseguida. En cuanto a Anselmo, valgan una indicación previa y tres diversas especificaciones de otras tantas «sombras» que en su aportación me place subrayar ante los alumnos, sin por ello pretender disminuir ante sus ojos la grandeza de dicha aportación, sino buscando más bien resaltarla como en un juego de claroscuro: la indicación previa quiere dejar constancia de mi debilidad por el autor de la así llamada - algo o muy impropiamente- prueba ontológica al que tantos estudios he dedicado a lo largo de mi vida académica (el último de los cuales valdrá aquí de testimonio: JosEP MANUEL UdINA, «Sant Anselm [10331109]», en AA. Vv., Història del pensament cristià. Quaranta figures [ed., P. Lluís], Proa, Barcelona 2002, p. 259 289); en cuanto a los puntos oscuros de Anselmo, se trata de su incapacidad para liberarse del esquema feudal de amo-siervo al referirse a la relación Dios-hombre (aspecto harto criticado tanto en mi introducción como en mis notas a mi traducción catalana de ANSELM de CANTERBury, Per què Déu es va fer home, Proa [Clàssics del Cristianisme 34], Barcelona 1992), de la ineficacia de su buena intención a la hora de adoptar una actitud verdaderamente dialogal y ecuménica con otras religiớnes o confesiones (cf. al respecto JOSEP MANUEL UDINA, «Sentido y límites del diálogo interreligioso en el autor del Cur Deus homo», en AA. Vv., Cur Deus homo. Atti del Congresso Anselmiano Internazionale: Roma, magio 1998 [ed., P. Gilbert, H. Kohlenberger y E. Salmann], Ateneo S. Anselmo [Studia Anselmiana 128], Roma 1999, p. 749-765) y, sobre todo, de la actitud -autoritaria, intransigente e incluso traidora- que adoptó con Roscelino y que llevó a la condena de éste sin mediación de diálogo alguno (penoso episodio que he expuesto muy críticamente en mi «Introducción» a ANSELM DE CANTERBURY, o. cit., p. 15-20 [«El "cas Roscelin"»], entre otros lugares). Por lo que se refiere al Aquinate, en fin, baste enumerar algunos de los aspectos menos transparentes o incluso harto inconsistentes y hasta contradictorios de su aportación: el mantenimiento de la tesis aristotélica de la individuación por la materia (incoherente, por ejemplo, con su teoría creacionista del alma individual), su incapacidad de superar el condicionamiento social de la época en sus juicios sobre judíos y musulmanes (tildándolos de gentiles o acusando a Averroes de doctrinas como la de la «doble verdad», cuando él mismo sería sin duda mucho más susceptible de ser acusado que el Comentador) y, muy particularmente, su indecisión —por sus vínculos con el papado- a la hora de posicionarse frente al tema del poder civil supremo, atribuído en la época por unos al papa y por otros al emperador).

14 En efecto: tanto su criptomaniqueísmo — que quizás fuera mejor denominar simplemente su incurable maniqueísmo-, en lo ético-moral, como su pesimismo antropológico, del que la doctrina de la predestinación no es sino fruto, han hecho mucho daño al cristianismo de los siglos posteriores. 
vicio ofrecido al estudiante, que ha de poderle ser a éste tan provechoso como es para él opcional. Es decir: a la obligación del profesor de impartir su curso, y ello lo mejor que sepa y pueda, no corresponde en el alumno la obligación de asistir a todas y cada una de las clases. Por esto, además de la Antología y del Dossier que pueden adquirir a principio de curso, al final de cada semestre mis alumnos tienen también a su disposición un Resumen de los temas del programa de la asignatura presentados y desarrollados en clase. ${ }^{15} \mathrm{El}$ puzzle de tres piezas se convierte, así, en uno de cuatro (la Antología, el Dossier, la docencia oral y su Resumen escrito); y con ello viene a exigirse al alumno un incremento de interactuación y de trabajo personal, ya de por sí siempre insustituíble, en su confrontación académica con la Historia de la filosofía medieval.

\author{
Josep Manuel Udina \\ Departamento de Filosofía \\ Universitat Autònoma de Barcelona \\ 08193 Barcelona \\ E-mail: udinabonet@hotmail.com
}

15 Como la Antología de textos y el Dossier de curso, este Resum dels temes d'història de la filosofia medieval es publicado también en edición limitada por la Universitat Autònoma de Barcelona, pero esta vez en sendos fascículos, al final respectivamente de cada uno de ambos semestres del año académico. El último de los aparecidos ( 80 p.) corresponde, pues, a enero de 2003 ; el otro ( 60 p.), a finales de mayo. 